\title{
A Study on Impact of System of Rice Intensification (SRI)Method of Paddy Cultivation on Production Level in Balaghat Block of District Balaghat
} (M.P.)

\author{
Ms. Minakshi Meshram ,Ms. Pooja Manjhi Dr. Sandhya Choudhary ,Dr. V.K. \\ Swarnakar.
}

\begin{abstract}
Rice is one of the most important and largest growing crop throughout the country as a food grain. In Madhya Pradesh State, rice is the staple food and it is grown in an area of 248.3 hectare with a production of 489.2(1000 Tones) and productivity of $2970 \mathrm{~kg}$ per hectare during 2013-14. . The new system of rice cultivation (SRI) came in India in the year of 2003-04 at Andhra Pradesh at first. Due to adoption of this technology farmers are getting 25-50 \% higher yield than traditional methods of paddy cultivation in the area. Hence, it becomes the popular among the paddy cultivators in Andhra Pradesh. Balaghat division of M.P. is one of the important paddy growing region of Madhya Pradesh with a view to enhance economic benefit from paddy cultivation with the adoption of system of rice intensification method of paddy cultivation. In relation to the production level of paddy among SRI technology practicing farmers, it was found that majority of paddy growers had medium production level.
\end{abstract}

Key Terms-Respondents :

Those rice growing farmers who were selected through simple random sampling without replacement.

Marginal farmer : A respondents with a land holding up to 2.5 acres.

Small farmer : : A respondents with a land holding 2.5 to 5 acres.

Medium farmer : A respondents with a land holding 5.01 to 10 acres.

Big farmer : A respondents with a land holding above 10 acres.

SRI : System of Rice Intensification

\section{INTRODUCTION}

System of Rice Intensification (SRI) is a new system of rice cultivation for increasing rice productivity with a comprehensive package of practices involving less seed, water, chemical fertilizers and pesticides. The system of rice intensification was first tried in Madagascar in1999 and since 2000, it has spread to many countries with spectacular results. The rapid dissemination of this system lies in the fact that it increases rice yields dramatically without requiring extra seeds, chemical fertilizers or other external inputs. The SRI efficiently uses scarce land, labour, capital and water resources, protects soil and groundwater from chemical pollution and is accessible to poor farmers. It is spreading fast because it is versatile and can more than double farmer's net income. In the light of the importance of SRI, this study has been under taken with the general objective of analyzing the performance of emerging technologies and their potential over the existing technologies and the pattern of adoption of new technologies by the farming community. The Balaghat is a major rice growing district of the state, where rice igrown in 2,44,483 hectares area with the total annual production of 2,46,491 tonnes (2013-2014) and an average yield of 1.10 tonnes/ha. The productivity of rice in the district is low as compared to the average yield of state and national level. In Balaghat block of Balaghat district, majority of the farmers grow paddy crop, where the total area under paddy crop is 25,495 hectare and total area under SRI 3,314 hectare.

Rice is one of the most important and largest growing crop throughout the country as a food grain. Looking to the higher demand of rice of growing population and the present situation of resource availability with farmers, particularly the size of land under cultivation of rice, production pattern there is a prime need for enhancing the production of rice to achieve the food security for future, there seems to be know other alternative except to adopt the improved/recommended rice production technology. The ultimate success of any developmental programme depends on the extent to which the farmers adopt the new ideas and practices. The new system of rice cultivation (SRI) came in India in the year of 2003-04 at Andhra Pradesh at first. Due to adoption of this technology farmers are getting $25-50 \%$ higher yield than traditional methods of paddy cultivation in the area. Hence, it becomes popular among the paddy cultivators in Andhra Pradesh. Balaghat division of M.P. is one of the important paddy growing region of Madhya Pradesh. With a view to enhance economic benefit from paddy cultivation with the adoption of system of rice intensification method of paddy cultivation, the scientist of K.V.K. and all agriculture department demonstrated this technology on the field of farmers. Due to low cost technology and high productivity area. the present study entitled "A Study on Impact 
of System of Rice Intensification (SRI) Method of Paddy Cultivation on Production Level in Balaghat Block of District Balaghat ( M. P.)" had been undertaken with the following specific objective.

\section{Objective;}

To study the production level of paddy through SRI technology practicing farmers.

\section{Review o9f Literature:}

Uprety (2004) reported that the average rice yield with SRI is 8 thac, whereas the yield is 3 tha under conventional paddy.

Udaykumar (2005) recorded by SRI method significantly higher seed yield/ha (2.94 t/ha) as compared to traditional method $(2.37 \mathrm{t} / \mathrm{ha})$. The per cent increase in seed yield per ha under SRI method was 20.25 over traditional method.

Sita Devi et. al. (2009) reported that highly significant association between contact with extension agencies with the production level. They further reported that highly significant association between farm size with the production level.

Patidar (2010) found that there was no significant association between size of family and utility perception of paddy growers in respect ICT.

Sangita (2010) reported that the net income increase with the increase in size of land holding in both SRI non SRI method of paddy cultivation. She further reported that there was marginal difference in educational level of SRI and non SRI method of sample respondents which shows that illiteracy may not considers as a constraints in adoption of SRI method of rice cultivation.

\section{METHODOLOGY}

For fulfilment of these objectives, the study was conducted in Balaghat district. Out of ten blocks of the district, Balaghat block was purposively selected for the study. The study was conducted in six selected villages where the SRI method of paddy cultivation has been popularized among the paddy growers by KVK, Balaghat through demonstration, trials, trainings and other extension activities. After the selection of villages, a village wise list of such farmers who were benefited from transfer of technology programmes of KVK concerned with SRI system of paddy cultivation was formulated and paddy growers were selected with proportional allocation method to make a sample of 120 farmers who adopted the SRI method of paddy cultivation. The data were collected using survey method through a pre-tested interview schedule and responses were recorded. Collected data were then tabulated and analyzed using appropriate statistical technique.

\section{VALIDITY AND RELIABILITY OF THE INSTRUMENTS}

Validity refers to whether the data collection instruments measure what is to be measured. Validity of interview schedule for this study was maximized by taking the following steps:

1. The interview schedule was thoroughly discussed with the members of the authority, advisory committee and their suggestions were incorporated.

2. Pre-testing of the interview schedule provided an additional check for improving the instruments.

3. The relevance of each question in terms of the objectives was checked carefully.

Reliability of an interview schedule refers to its consistency. It has been observed properly, that the interview had reliability before it was used as a data collection instruments.

\section{RESULT \& DISCUSSION:}

Adoption level of SRI technology :

Table : Mean score of Adoption among SRI

\begin{tabular}{|l|l|c|c|}
\hline S. No. & Technological components & Mean score & Rank \\
\hline 1. & Land preparation & 10.59 & III \\
\hline 2. & Fertilizer management & 4.69 & VI \\
\hline 3. & Seed sowing and transplanting & 18.49 & I \\
\hline 4. & Weed management & 2.87 & VII \\
\hline 5. & Plant protection management & 6.44 & V \\
\hline 6. & Harvesting and threshing & 10.50 & IV \\
\hline 7. & Storage & 11.45 & II \\
\hline & Overall mean $(\mathrm{X})-$ & 9.29 & \\
\hline
\end{tabular}

The technological components of rice production technology in which the paddy growers were having mean score higher than the overall mean were seed sowing and transplanting as it has received Ist rank, followed by storage, Land preparation and harvesting and threshing management. The technological components which have lower mean score than the overall mean were plant protection management which received Vth rank, 
followed by fertilizer management, and weed management. Thus it can be concluded that important technological components of the paddy growers were :

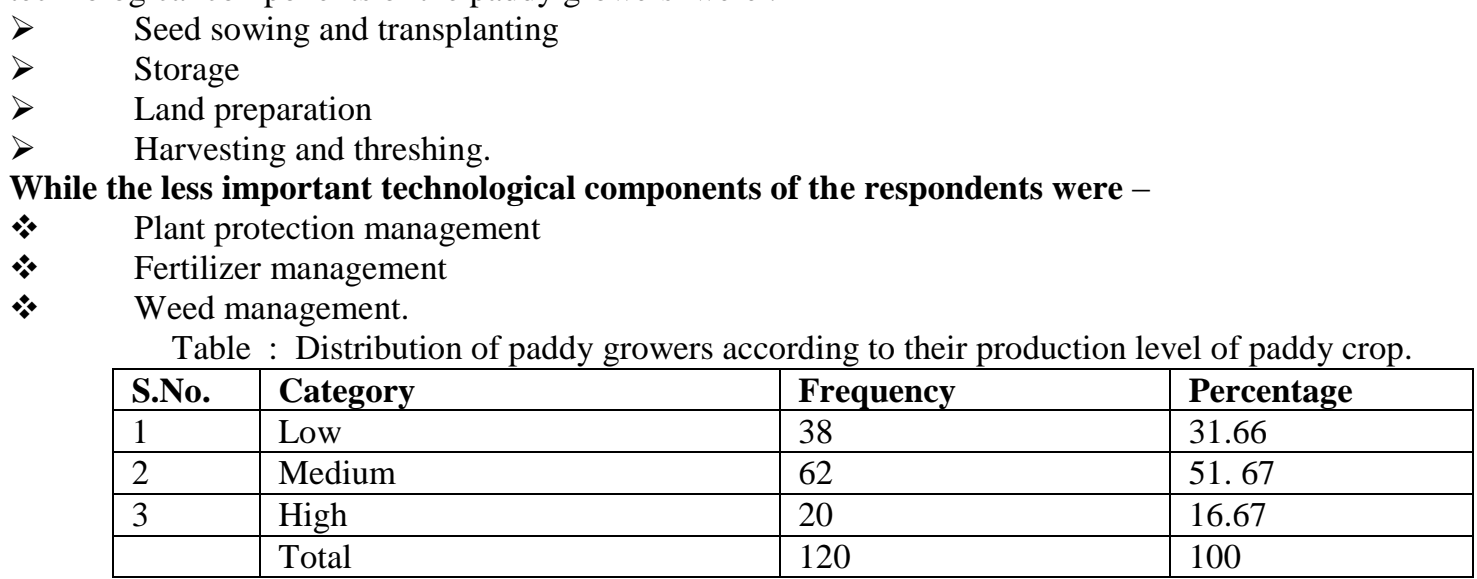

The data of above Table reveals that out of total paddy growers, 51.67 per cent had medium production level, while 31.66 per cent low, whereas only 16.67 per cent high production level of paddy. Thus, it may be concluded that majority $(51.67 \%)$ paddy growers had medium production level among SRI technology practicing farmers.In relation to the production level of paddy among SRI technology practicing farmers, it was found that majority of paddy growers has medium production level.

\section{REFERENCES}

[1] 1Patidar , J. (2010), Study on utility perception and expectation of paddy growers, regarding information communication technology in Hanumana block of Rewa district (M.P.),M.Sc.(Ag.) Thesis ,JNKVV

[2] 2Sivanagaraju P.(2006), Traditional and SRI method of paddy cultivation - A comparative economic analysis. M.Sc. Ag. Thesis, Dharwad university of Agricultural sciences.Dharwad.,Jabalpur.

[3] Rahangdale Deepti (2011), A study on impact of System of Rice Intensification (SRI) method of paddy cultivation on production level in Balaghat block of District Balaghat (M.P.) M.Sc. (Ag.) Thesis ,JNKVV, Jabalpur.

[4] Ranikumar, K.N., Bapuji Rao,B. and Shree. Lakshmi,K. (2004). Economics of major farming system in the north coastal zone of Andhra Pradesh. Manage Extension Research Review, 5(1): 10-32.

[5] Uphoff, N. (2002); paper presented in International year of Rice conference, FAO, Rome. Feb 12-13, 2004.

[6] Uphoff, N. (2002); paper presented in International year of Rice conference, FAO ,Rome. Feb 12-13, 2004.

[7] Uprety. R (2004). Performance of System of Rice Intensification in Morang dist. http \I Ciifad. Cornell. Edu / sri countries / Nepal / nealrprety 041.pdf.

[8] Verma, H.K. and Jana, J. (2004). Constraints faced by the paddy growers in the adoption of recommended plant protection practices. Rural India, 64 (541): 122.

[9] *M.Sc. Students 2016, College of Agriculture, Indore

[10] ** Associate Professor, College of Agriculture, Indore

[11] ****Professor \& Head of Extension Education, College of Agriculture, Indore 